2009

\title{
Discourses for Social Justice Education: The Web of Racism and the Web of Resistance
}

Lisa Werkmeister Rozas

University of Connecticut

Joshua Miller

Smith College, jlmiller@smith.edu

Follow this and additional works at: https://scholarworks.smith.edu/ssw_facpubs

Part of the Social Work Commons

\section{Recommended Citation}

Rozas, Lisa Werkmeister and Miller, Joshua, "Discourses for Social Justice Education: The Web of Racism and the Web of Resistance" (2009). School for Social Research: Faculty Publications, Smith College, Northampton, MA.

https://scholarworks.smith.edu/ssw_facpubs/11

This Article has been accepted for inclusion in School for Social Research: Faculty Publications by an authorized administrator of Smith ScholarWorks.

For more information, please contact scholarworks@smith.edu 
Web of Racism and Web of Resistance Page 1 of 21

Discourses for Social Justice Education: The Web of Racism and the Web of Resistance 


\section{Introduction}

Social justice education strives to motivate students to analyze the dynamics of oppression while being able to situate themselves as social actors. This involves learning about the sources and processes of oppression as well as the interior psychological/emotional consequences of oppression without remaining neutral: social justice education seeks to change the conditions being studied and to work for greater equality and fairness (Bell, 1997). Thus, when using a social justice framework to teach about race and racism it is important to strike a balance between presenting the grim realities of racism in a direct, unvarnished manner, while also engendering, if not inspiring, hope for change. Students enter such classes with widely differing experiences and understandings of racism adding to pedagogical complexity (Miller \& Garran, 2007). Students and instructors bring a variety of social identities into a classroom; ranging from identities forged through frequent encounters with racism to those living in bubbles of unexamined white privilege. Many people harbor stereotypes which may cause discomfort and inhibit classroom participation if conscious, or lead to overt expressions of prejudice and microaggressions (Dovidio, Gaertner, Kawakami, \& Hodson, 2002; Solorzano, Ceja, Yosso, 2000). The potential for conflict and misunderstandings is great when a group of people with such different experiences talks about such emotional and highly charged material (Miller, Donner \& Fraser, 2004). People of color may feel retargeted while those with race privilege may withdraw or be consumed by guilt, leaving everyone feeling overwhelmed and hopeless. Yet another challenge is that the language 
and meaning of terms and concepts often varies such that the use of the word 'racism' can range from internalized prejudices and biases to institutional systems of oppression.

In this article we consider these challenges and propose two related concepts that can further productive classroom discussion and enhance student learning: the web of racism and the web of resistance. The first helps students grasp the extent and depth of institutional racism in the United States today, while the second offers a map of activities that can lead to social change and foster solidarity with others. Both concepts assume that racism is an external, systemic, socia/economic/political force which also has subjective correlates that become part of a person's inner world. These inner and outer realities intersect and reinforce one another, part of the dynamic that sustains "durable inequalities.” (Tilly, 1998).

We begin by expanding our analysis of the problems inherent in teaching students of different social identities about race and racism, particularly looking at dissonance between the realities of racism and the way it is perceived by people with race privilege. We then introduce a number of conceptual frames which help students to develop a common language and understanding of the racial project in the United States (Omi \& Winant, 1994): the racial contract (Mills, 1997); subjugated histories (Takaki, 1993); cycles of socialization (Harro, 2000a); and invisible white privilege (McIntosh, 1989, 1992; Wise, 2003, 2004). These frames underpin an understanding of the concept of the web of institutional racism (Miller \& Garran, 2007). We then consider how to move from students feeling overwhelmed by the depth and magnitude of racism by offering hand-holds of hope through the concept of the web of resistance. If racism can be grasped and acknowledged by all students, then breaking down antiracism work into 
achievable, interconnected action steps, which respond to internal and external manifestations of racism can lead to inspired activism.

A brief note about our language - we will use the terms "white" and "people of color", not because this signifies any biological or genetic reality, but rather because these are terms in common usage in the U.S. referring to those with or without race privilege. While we are usually referring to people of European descent as white and people of African, Asian (and Pacific Islander), Hispanic, and Native American as people of color, we recognize that racial categories are continually being recast and reconfigured. We also acknowledge that many people are multi-ethnic or multi-racial and that racial identity involves a complex and unique set of factors.

The Prevalence of Racism and its Denial by many White People Despite many studies attesting to the persistence of racism (e.g. Brown, Carnoy, Currie, Duster, Oppenheimer, Schultz \& Wellman, 2003; Smelser, Wilson \& Mitchell, 2001; Shapiro, 2004) many people socially constructed as white deny or minimize its existence. "I'm not racist" is a phrase uttered by well meaning whites when confronted about a racist comment or action, often implying that if they are not conscious of engaging in racist acts, then not only are they not racist but that racism is not a salient social problem. Recent high-profile examples of this stance have been seen with radio talk-show host Don Imus and actor comedian Michael Richards (Pitts, 2006).

Why is racism is so difficult for many white people to acknowledge? Ignorance, internalized stereotypes and defensiveness are bolstered by prevalent and dominant discourses asserting that racism is a thing of the past and enough has been done to rectify disparities that used to exist. Many polls find a stark gap between whites and blacks 
about the depth of racism today (Dawson, Lacewell, \& Cohen, 2006; Pew Research Center, 2003). How is it possible that people living in the same society have such different perceptions about race and equality?

Perhaps part of the discrepancy has to do with how racism is understood or defined. For many people, particularly whites, the concept of racism has been relegated to individual feelings, acts, or utterances that intentionally insult, disrespect, or devalue another person because of race. The perception that racism is limited to conscious beliefs and interpersonal situations is what many white students believe when they enter a class that discusses issues of power, prejudice, privilege and injustice. The realization that racism is much more pervasive and is embedded in seemingly race neutral institutions and policies creates great dissonance. Many, if not most, whites grow up with the belief that the United States is the land of opportunity and equal justice for all, where their ancestors achieved the "American Dream" through hard work. The myth that the “American Dream" is within everyone's grasp is not innocuous, leading some to conclude that the poor and people of color are responsible for their own lack of progress.

It is important that white students acquire relevant information regarding racial disparities such as that in $2005,75 \%$ of whites owned their own homes compared to $46 \%$ of black households and $48 \%$ of Latino households, and the median income for whites was $\$ 50,622$ as apposed to $\$ 30,939$ for blacks and $\$ 36,278$ for Latinos (2005 census as cited in Ohlemacher, 2006). However, even when confronted with such discrepancies, some white people remain skeptical. Confronting students with facts is insufficient, conceptual frames are needed to penetrate defensive reactions and denial: what are needed are new maps and discourses. 


\section{Conceptual Frames for Talking about Racism}

There are a number of conceptual frames which we have found to be valuable for students engaged in antiracism that help to overcome the dissonance described above: the racial project, the racial contract, reclaiming subjugated histories, cycles of socialization and invisible white privilege. All of these offer a foundation for understanding the web of racism, which helps students to actually see the ways how racism forms a net that limits hope and opportunity for many people of color, while remaining virtually undetectable for those with white skin privilege.

$\underline{\text { The Racial Project }}$

Omi and Winant (1994) conceive of racism as a project, which has been central to U.S. history and which adapts, mutates and evolves; racism does not look the same in different eras but it is always there. The project involves "racial formation" (p. 55) where racial categories are created by socio-historical and political forces based on the meanings attributed to the alleged differences of human body type. Thus, racial categories are not fixed and unchanging; rather they are socially constructed, deconstructed, reworked and reconfigured. An example of this is how Jews and Italians were socially constructed as racial and cultural "other" by native Anglo-Americans when they immigrated in large numbers to this country - viewed as being dark-skinned, uncivilized, deviant and even dangerous - but after one or two generations became white and able to assimilate into U.S. society.

Omi and Winant (1994) illustrate how racism is embedded in social structures as well as in cultural representations, which include social meanings and political ideologies. In other words, racism is present in institutions, cultural practices, political processes, and 
economic structures, but it also lurks inside of people and influences and constrains social relationships. A major role in maintaining the racial project resides with the racial state.

\section{The Racial Contract}

Mills (1997) helps to explain how the racial state was formed through his notion of the "racial contract." Most people in the U.S. are aware of a social contract, embodied in the Declaration of Independence and U.S. Constitution, with articulated rights and privileges. Mills argues that there was always an underside to the social contract, a racial contract, serving as a political, epistemological and moral guide to who was or was not considered fully human. Considering how most of the "founding fathers" were slaveholders, there was a dualism between the ideals and values of their words and the assumptions of racism in their deeds. Thus the racial contract was enshrined in a racial state and racial judicial system. It was also a tacit part of the social contract that established what is socially right, fair, objective and normal.

As Omi and Winant (1992) have argued, the racial project evolves, and this helps to explain how the racial contract still exists, although no longer appealing to outright theories of racial inferiority which were front and center at its inception. Mills (1997) states that all whites have benefited from the racial contract, even if they were not "signatories," yet, ironically, are unable to see and grasp the social order in which they swim freely, unimpeded by their race. The next three conceptual frames help to explain this contradiction.

\section{$\underline{\text { Subjugated Histories }}$}

Visions of U.S. society (and literally the vision needed to discern and decipher racism) are sustained by narratives about the nation. The roots of these narratives are 
"official" stories about the history of the United States. This is a required topic for all school children in the country, as well as a subject of many books (both fiction and nonfiction), films, television shows, paintings, songs and other cultural, political and artistic mediums of expression. These narratives and images become part of a person's internal world, the maps and metaphors of consciousness and identity which are used to see, comprehend and navigate the world.

It is common wisdom that history is written by the victors, and in this nation the prevailing historical narratives and paradigms have been the history of the white race. This is so commonplace that it can be jarring for many students to read the above sentence. Yet without alternative narratives and perspectives, it is difficult for anyone to understand the socio-political complexity of the past and how the racial contract and racial project have been manifest throughout U.S. history as well as in contemporary society. Thus it is essential to expose students to critical and revisionist histories, those that revisit, interrogate, deconstruct and re-story the experiences of people in the United States from the standpoint of a wide range of ethnic and racial groups. Takaki (1993) attempts this in a broad way in $\underline{\text { A Different Mirror }}$, where he charts the experiences of many groups, such as Native Americans, African Americans, Chinese Americans, Japanese Americans, Mexican Americans and others, whose history has either been ignored, distorted or relegated to sidebars, from the perspective of those groups, not from the vantage point of European Americans. It is also important for students to have an understanding of indigenous peoples' lives before the European contact and to see how drastically they changed after the Columbian encounter (Stannard, 1992; Wilson, 1998). Other examples of historical studies which challenge prevalent understandings of racial 
formation are Allen's (1997) examination of how the white race was “invented," Lopez's (1996) account of how race was legally constructed, or the numerous studies about how ethnic groups, such as Jews, the Irish and Italians, became "white" (e.g. Guglielmo \& Salerno, 2003; Ignatiev, 1995; Sacks, 1996). Introducing students to critical histories offers new pathways of understanding how today's racist society evolved.

\section{Cycles of Socialization}

Indoctrination with triumphalist narratives of white people, presented as "objective" history is but one way that people are socialized into the racial project in the United States. Harro (2000a) offers a model that describes the myriad ways that white people are socialized into positions and perceptions of superiority, while people of color are socialized into targeted status with her "cycle of socialization." She maps out an indoctrination process that is pervasive, consistent, recursive, self-regenerating and is often unconscious and unnamed, rendering it invisible to many.

The model identifies core factors which fuel the cycle: learned fear and insecurity, ignorance, myths and misinformation, pessimism. Harro (2000a) argues that people enter a world where their social identity (race, ethnicity, religion, gender, sexual orientation, etc.) influences what they are taught, how they are treated, and what information and opportunities they are exposed to. One of the most poignant aspects of her model is articulation of who exposes young people to stereotypes, prejudices, expectations, understandings of the world - what is "normal": trusted others (parents, teachers, family, friends). She describes how the structuring of society - institutions, discourses, sanctions and rewards, cultural practices - reinforces what has been learned from trusted others. All of this leads to internalized patterns and maps of power, privilege or of impotence, 
devaluing, and feeling disempowered, which contributes to the cycle continuing. The "cycle of socialization" graphically depicts how racism and other forms of social oppression saturate society and drench and penetrate inner psyches.

Invisible White Privilege

Race privilege is very visible for those who lack it, but it is remarkably undetectable for those who have it. Mill's (1997) "racial contract" and Harro's (2000a) "cycle of socialization" describe how white privilege has been enshrined since the inception of the U.S. republic and how it has been passed down - institutionally, interpersonally, and intrapersonally - for generations. In addition to describing how this happens, it is important to help students (particularly white students) to see the results. McIntosh $(1987 ; 1992)$ used the metaphor of carrying a "knapsack" of invisible white privileges and she listed many examples of the knapsack's provisions. Here is a sample:

- To be able to consistently be in the company of people of your own race.

- To be able to move to live in whatever neighborhood you can afford.

- To not be followed when shopping.

- To see yourself widely (and for the most part positively) represented in the media.

- To not have to protect your children from racism.

- To not be considered a "credit to your race" when you excel.

- To not have to worry if stopped by the police or audited by the IRS that it is because of your race.

- To find greeting cards, dolls and toys depicting people who look like you. In our teaching experience, McIntosh's examples are evocative for people of color who have not had these privileges but are particularly illuminating for many white 
students who have not thought a lot about their invisible privileges. As Wise (2003) describes, there is a "sea" of white privilege, and for most fish, water is an assumed part of the environment. Thus, having classroom exercises, whether they focus on what constitutes this ocean of privilege or what is packed in an invisible knapsack, can be validating for students of color while revealing what has heretofore been hidden from many white students.

The Web of Institutional Racism

All the above conceptual frames lay a foundation for helping students grasp the web of institutional racism (Miller \& Garran, 2007). The web is a centerpiece of the racial project, enshrined by the racial contract, masked by distorted, incomplete historical and contemporary narratives, and legitimized and reinforced by cycles of socialization, which rationalize oppressive social structures while creating corresponding psychological interiors. The web of institutional racism snags and hinders most people of color in at least some of its nets, while the vast majority of white people neither sees nor experiences it, carrying invisible passports of white privilege.

The web of institutional racism (Figure 1) names some but not all of the forms of institutional racism. The different aspects of institutional racism are connected and reinforce one another. For example, residential racism is very tied to educational racism and environmental racism, which connect with health racism, and all lead to differential opportunities for upward mobility based on the social construction of race. Miller and Garran (2007) highlight five qualities of the web:

1. It is systematic and comprehensive. 
2. It functions on many levels - e.g. educational racism involves unequal funding of schools on the macro level, insufficient numbers of teachers and administrators of color at the mezzo level, and students of color experiencing microagressions at the micro level.

3. The web is a combination of formal policies (e.g. laws, regulations, hiring practices, etc.) and informal practices (e.g. doctors and therapists treating people of color differently, redlining residential areas.)

4. The web is a culmination of centuries of institutional racism and its legacy results in cumulative deprivations and lack of opportunity.

5. The web represents social, political and economic power and therefore has the capacity to shape public narratives and discourses, many of which obscure, obfuscate and deny the existence of the web!

The web of institutional racism is both a metaphor and a description of concrete realities. It provides scaffolding for teaching an entire course about racism or can be used as part of a course that covers the full spectrum of racism. Conceptually it is important to help students grasp how the different parts of the web intersect and connect.

Understanding institutional racism is pivotal to understanding any other form of racism, ranging from state sponsored genocide to internalized biases and prejudices.

An unintended consequence of using the web of racism when teaching is that absorbing the magnitude and depth of racism can lead to feelings of hopelessness, despair, pessimism, and fatalism. I is important that students have hope, efficacy and empowerment. This is why we have developed the concept of the web of resistance. 
Students often find courses on racism or other forms of oppression to be depressing and demoralizing. After hearing of the historical context of racism and its present day consequences, many feel helpless, believing that change is impossible. Issues of having a privileged or targeted identity arise as well as powerful feelings, such as anger, despair, guilt and shame. Presenting the web of resistance is an intervention that unites students and sends a message of hope in their ability to take part in change.

Change is facilitated with a vision of an alternative culture; in this case an antiracism culture. In his view of how anti-oppressive cultures are created, Paulo Feire (1976) emphasized the creation of critically conscious individuals. The way to establish this type of consciousness is by instituting two critical dimensions: action and reflection. These two factors create "praxis" which is the actual process of informed action. The web of resistance has a similar theoretical underpinning. It is illustrated in Figure 2, demonstrating some but not all approaches to undoing racism. The web of resistance has two main components that are the source for all informed efforts to end racism: internal strategies and external strategies. Internal strategies focus on what is required of the individual who attempts to participate in an anti-racism movement - efforts and tactics focusing primarily on the development of an inner capacity to engage in resisting racism. External strategies are aimed at ongoing action, created in alliance or coalition with others. These involve action-oriented activities that help to dismantle the forms of racism cited in the web of racism. These two overarching strategies are connected to each other via points of connectedness (P.O.C).

These P.O.Cs are intersections on the web of resistance where an individual can build a network within herself and with other people interested in anti-racist activism. 
Each P.O.C. offers a specific approach that can be used in the effort to undo racism. P.O.Cs interact with one another, strengthening an individual's resolve, commitment and ability to undo racism. P.O.Cs construct a formidable support network in the struggle to end racism. Although a change in an individual's internal strategies can eventually lead to the P.O.Cs stemming from external strategies, there are some people who value and believe in antiracism but do not yet have the tools or support to enable them to take action. Over time, their internal work may eventually lead to informed action resulting in external activities. Taken together, P.O.Cs originating from both internal and external strategies are defenses against the web of institutional racism.

\section{Internal Strategies}

All of the P.O.Cs that stem from internal strategies support enhancing selfawareness and reflection. The most important element is to be an active participant in a self-reflective process (Dovidio et al, 2002). This process is often jumpstarted by a student's new found awareness of how they have been socialized without knowledge or consent (Harro, 2000a). In her cycle of liberation, Harro (2000b) calls this part of the process "waking up" and "getting ready" (465). Both these phases require a different self-perception which is fostered by participation in exercises which encourage selfawareness, discovery, and education (Harro, 2000b; Miller \& Garran, 2007).

Several P.O.Cs consist of skills that cultivate ability to experience emotions that are uncomfortable. For example, a person can write their reflections, share them with others, listen to other people's experiences, or learn to tolerate and sit with feelings. What is crucial is being able to confront the long held discriminatory and biased beliefs spawned by misinformation and stereotypes that devalue one group and overvalue 
another. Educating oneself is a critical aspect to the internal portion of the web. All these strategies offer an opportunity to be empathic either with oneself or others who are stuck in the web of racism and are struggling to build the web of resistance.

Although it is difficult for someone with white skin privilege to have a completely accurate view or feeling of what it means to be part of a racially targeted group in this country, people can attempt to understand part of the process through engaging in a P.O.C which one student of ours called "mental math." Mental math is the process many people of color go through as a result of racism, discrimination, and prejudice. Was the person just rude, or is it because of my skin color being dark? That my surname has Latino roots? That my articulation of certain words does not fit that of the dominant group? That my facial features relegate me to "other" status? Could one of these target determinants be responsible for what occurred between me and a person from the dominant group?

White people generally do not have to ask themselves these questions or spend time processing the event in order to make sense of it while for people of color this process of mental math is automatic and tiring. Thus, if white people can empathically experience "mental math", through role-plays, simulations and discussions they may begin to grasp the kind of energy needed to partake in simple cross-racial interactions. This helps with personalizing the experience and understanding how white privilege, power and racial microaggressions work.

\section{External Strategies}

Emanating from the external strategies are the P.O.C's that help to establish common ground and ongoing action. Harro (2000b) has three phases in the cycle of 
liberation that overlap with the external strategies in the web of resistance. In the cycle of liberation, "reaching out" comes after a time of introspection. It is marked by the individual needing to go outside of herself in order to experience who she has become in the presence of others. With the interaction with "other" comes the "building community" phase where people are drawn together because they have similar values and goals of antiracism to attain. Dialogues occur to help strengthen new found values. With this new found support the next phase "coalescing" develops. As action strategies are developed and a refusal to collude with the forces that perpetuate racism is solidified, students begin to identify with activism.

The external strategies that exist in the web of resistance produce P.O.Cs which constitute actions resulting in a disruption in the belief that racism is the status quo. Examples of external strategies are solicited from students, creating a cache of approaches that can be conducted individually or collectively. Alliances are made with other individuals who have similar values and are seeking to be involved in anti-racist action. These individuals both support and constructively challenge each other to go further in their own process while making strides to stand up against institutional forces that harbor and perpetuate racism. Whites team up with people of color with whom they have found common ground to provide strength when confronting racist policies and practices or lobbying for legislation that could diminish racial disparities in housing, healthcare, and employment. Whites form important alliances and organizations with other whites to utilize their power and privilege to fight for racial equity in schools. They not only focus on ongoing action but on ongoing self-reflection. People of color also come together to strategize about what they need for their communities and how they can 
make use of the active support of their white allies. It is through our active engagement and connection (Miller \& Garran 2007) with other people and larger communities that we begin to create change in the culture of racism.

It is through the bi-directional flow of the web of resistance's POCs that guilt, anger, and frustration are transformed into acts of justice. Each POC shores up the other. The internal strategies help to sustain the external strategies and visa versa. It is an enduring process of equality. Each person involved in the web, each act committed through the support of the web becomes a strand whose very presence is an act of defiance. One student's reaction to the web of resistance was to find it "powerful, not symbolic in isolation but symbolic coupled with quiet action and commitment to the shared pursuit of social justice, infusing the role of "resister" into her identity.

Five qualities can be seen as salient to the web of resistance:

1. It is an evolving process

2. It functions on many levels (e.g. discovering one's own racism as the result of socilialization or interrupting racist jokes on a micro level, establishing a work group to address issues of racism in an organization, on a mezzo level, and institutions utilizing programs such as affirmative action or equal opportunity employment strategies, on a macro level.

3. The web is a combination of internal strategies (self-reflection, self-education) and external strategies (challenging others, challenging policies).

4. The web is the result of the legacies of committed anti-racist activists who have sacrificed many things to move an agenda of equality and social justice. 
5. The web represents hope, resilience, and collective power that can be used to dismantle the strong hold of racism.

\section{Conclusion}

As educators when teaching about race and racism, it is our responsibility to provide students with frameworks that help them understand macro-social factors that have contributed to racial inequalities. The web of institutional racism gives students a common language with which to discuss such injustice, so that they can begin the process of identifying dissonance between their prior beliefs and understandings and current, persistent inequalities based on race. At the same time, it is crucial that students be left with hope for change. They must believe that they can become a part of a system that resists the racist forces embedded in our society's current and historical structure. The web of resistance offers both hope and explicit strategies to undo racism.

By teaching this conceptual framework to our students we offer them strands of connections that when tested become stronger. Together, students begin to formulate an identity of strength, equity, collaboration, and pride that becomes the essential fiber of efforts to resist. They learn that the very people they have been sitting next to in class are the individuals they need to work with to create a web of resistance. It is essential that we teach our students, not only the tools by which racism can be dismantled but how to build support and alliances to further their goal.

\section{References}

Allen, T.W. (1997). The invention of the white race, Vol.2: The origin of racial oppression in Anglo-America. NY: Verso. 
Brown, M.K., Carnoy, M., Currie, E., Duster, T., Oppenheimer, D.B., Shultz, M.M., \& Wellman, D. (2003). Whitewashing race: The myth of a colorblind society. Berkeley, CA: University of California Press.

Burnett, R. (Executive Producer). (2006). Late show with David Letterman. [Television Series]. New York. CBS.

Dawson, M., Lacewell, M., Cohen, C. (2006). Racial attitudes and the Katrina disaster study. University of Chicago, Center for the Study of Race Politics and Culture.

Dovidio, J.F., Gaertner, S.L., Kawakami, K., \& Hodson, G. (2002). Why can't we all just get along? Interpersonal biases and interracial distrust. Cultural Diversity and Ethnic Minority Psychology, 8(2), 88-102.

Freire, P. (1979). Pedagogy of the oppressed. New York: Continuum.

Guglielmo, J. \& Salerno, S. (2003) (Eds.). Are Italians white: How race is made in America. NY: Routledge.

Harro, B. (2000a). The cycle of socialization. In M. Adams, W.J. Blumenfeld, R. Casteneda, H.W. Hackman, M.L. Peters, \& X. Zuniga (Eds.) Readings for diversity and social justice: An anthology on racism, anti-Semitism, sexism, heterosexism, ableism, and classism (pp. 15-21). NY: Routledge.

Harro, B. (2000b). The cycle of liberation. In M. Adams, W.J. Blumenfeld, R. Casteneda, H.W. Hackman, M.L. Peters, \& X. Zuniga (Eds.) Readings for diversity and social justice: An anthology on racism, anti-Semitism, sexism, heterosexism, ableism, and classism (pp. 463-469). NY: Routledge.

Ignatiev, N. (1995). How the Irish became white. NY: Routledge.

Kivel, P., (1996). Uprooting racism: How white people can work for racial justice. Gabriola Islands, BC: New Society Publishers.

Lopez, I.F.H. (1996). White by law: The legal construction of race. NY: New York University Press.

McIntosh, Peggy (1992). White Privilege and Male Privilege: A personal account of coming to see correspondences through work in Women's studies. Anderson, M \& Collins, P. H. (Eds.) Race, Class and Gender: An Anthology. Belmont, CA.: Wadsworth. pp. 70-81.

McIntosh, P. (1989). White privilege: unpacking the invisible knapsack. Peace and Freedom. July/Aug. pp. 10-12.

Miller, J., \& Garran, A.M. (2007). Racism in the United States: Implications for the helping professions. Belmont, CA: Thomson/Brooks-Cole. 
Miller, J., Donner, S., \& Fraser, E. (2004). Talking when talking is tough: Taking on conversations about race, sexual orientation, gender, class, and other aspects of social identity. Smith College Studies in Social Work, 74(2), 377-392.

Mills, C.W. (1997). The racial contract. Ithaca, NY: Cornell University Press.

Ohlemacher, S., (2006, November 14). Racia disparities persist despite civil rights gains. Miami Herald. Accessed on 11/27/06 at http//www.miami.com/mld/Miamiherald/news/politics/elections/16005913.htm

Omi, M., \& Winant, H. (1994). Racial formation in the United States: From the 1960s to the 1990s (2nd ed.). NY: Routledge.

Pew Research Center (2003). The political landscape: Evening divided and increasingly polarized. (Part 5 Social and political attitudes about race). Accessed on 12/1/06 at http//www.people-press.netcampaign.com/reports/display.php3?PageID=754

Pitts, L., (2006, November 26). Worse then Richard's rant: America's refusal to acknowledge racism. [oped]. The Baltimore Sun. Accessed on 12/1/06 at $\mathrm{http} /$ /www.baltimoresun.com/news/opnion/oped/balop.pitts26nov26,0,4427975.story?coll =bal-oped-headlines

Sacks, K.B. (1996). How did Jews become white folks? In S. Gregory \& R. Sanjek (Eds.) Race (pp. 78-102). New Brunswick, NJ: Rutgers.

Shapiro, T.M. (2004). The hidden cost of being African American: How wealth perpetuates inequality. NY: Oxford.

Smelser, N.J., Wilson, W.J. \& Mitchell, F. (Eds.) American becoming: Racial trends and their consequences, Vol. II. Washington, DC: National Academy Press.

Solorzano, D., Ceja, M., \& Yosso, T. (2000). Critical race theory, racial microaggressions, and campus racial climate: The experiences of African American college students. The Journal of Negro Education, 69(1/2), 60-73.

Stannard, D.E. (1992). American holocaust: The conquest of the New World. NY: Oxford.

Takaki, R. (1993). A different mirror: A history of multi-cultural America. Boston: Little, Brown.

Tilly, C. (1998). Durable inequality. Berkeley, CA: University of California Press.

Wilson, J. (1998). The earth shall weep: A history of Native America. NY: Grove. 
Wise, T., (2004). White whine: Reflections on the brain-rotting properties of privilege. Accessed on 12/12/06 at http://www.zmag.org/sustainers/content/2004$\underline{04 / 20 \text { wise.cfm }}$

Wise, T. (2003). Whites swim in racial preference. Accessed on 12/15/06 at http://www.alternet.org/story/15223/ 